\title{
Mate Retention Behaviours and Jealousy in Hypothetical Mate-Poaching Situations: Measuring the Effects of Sex, Context, and Rivals' Attributes
}

\author{
Bruna S Nascimento ${ }^{1}$ D $\cdot$ Anthony Little ${ }^{1}$
}

Published online: 31 July 2019

(C) The Author(s) 2019

\begin{abstract}
Individuals have been found to perform a range of behaviours to retain their partners. This study investigated whether potential rivals' attributes and the situation influence individuals' intentions to display these mate retention strategies. University students (119) were assigned either to the university party or academic event situation. After reading each of five different scenarios manipulating a potential rival's characteristics (social dominance, status, physical dominance, physical attractiveness and seductive behaviours), participants reported their intentions to use mate-retention strategies in the presence of rivals possessing each of the attributes above. The situation did not significantly influence the frequency of mate retention. Individuals reported higher intentions to use mate-retention strategies in the presence of attractive and seductive rivals in comparison to the other attributes. These differences were stronger among women than men. Overall, this study demonstrated that the attributes of a potential rival play an important role in determining the frequency of mate-retention strategies.
\end{abstract}

Keywords Rivals' attributes · Mate-retention strategies $\cdot$ Sex differences

Darwin's theory of sexual selection suggests that individuals within one sex compete for access to mates of the opposite sex (Darwin 1871). This process is called intrasexual competition and has been documented in humans (e.g. Hudders et al. 2014). Because men and women are free to choose their partners, the preferences of the opposite sex were the primary force shaping intrasexual competition (Miller 1998). Hence, to attract the best possible partner, the focus of individuals' efforts is determined by what attributes the desired men or women value in a prospective partner (Campbell 2013). For example, if women prefer men who are good at playing word games, the best male word game-player will be the most desirable partner for women. Thus, men will do their best to become good word game-players to enhance their mate value. Accordingly, the ability to play word games will become the focus of male intrasexual competition, such that men will perceive the best male game-players as great threats.

Bruna S Nascimento

bruna.s.nascimento@hotmail.com

1 University of Bath, Claverton Down, Bath BA2 7AY, UK
Confirming the role of preferences in intrasexual competition, studies have shown that given the opposite-sex preferences for certain attributes, individuals will become more vigilant towards same-sex individuals who display such attributes, especially in the context of mate attraction (Fink et al. 2014).

Recent research suggests that individuals in committed relationships are sensitive to cues of high mate-value in samesex individuals which, in turn, triggers the use of materetention strategies (Davies and Shackelford 2017), tactics used to preserve a long-term relationship (Buss 1988). However, such studies have focused on specific attributes, such as physical attractiveness in women and high status in men. In addition, the attributes of the threatened individual have been overlooked. Given that the quality of the mates we can attract and retain is constrained by our own value as a mate (Conroy-Beam et al. 2016; Millar et al. 2018), it is necessary to consider this factor when investigating how threatening a same-sex individual is perceived to be. Furthermore, most studies on mate-retention strategies are correlational, limiting the conclusions that can be drawn from them. Therefore, the current study investigated whether rivals' attributes affect individuals' intentions to display materetention behaviours, through a comparison of different rivals' attributes (e.g. physical attractiveness, status, popularity). 


\section{Ideal Partner Preferences}

To understand how the attributes of a potential rival may influence mate retention, it is important to understand which attributes men and women value in a partner. Evolutionary theory asserts that there are two main variables that affect partner preferences, namely sex and the temporal context of the relationship sought, whether short-term or long-term (Buss and Schmitt 1993). Men value characteristics linked to reproductive value (e.g. youth and physical attractiveness) more than women do, whereas women attribute more importance to characteristics related to social status than men do (Buss and Schmitt 2018). Both sexes value physical traits and sex drive relatively more for short-term than long-term relationships (Regan et al. 2000) but men are more willing to lower their standards overall for short-term relationships than women (Buss and Schmitt 1993, sexual strategies theory). However, some studies have not shown sex differences. In a study of face-to-face contact with a potential partner, both men and women were more interested in a potential romantic partner if they were attractive and presented high-earning potential (Eastwick and Finkel 2008; Selterman et al. 2015). These findings demonstrate that in hypothetical contexts, men's and women's partner preferences appear to differ, whereas in a more naturalistic context, men and women place importance on similar attributes in a romantic partner. However, the face-to-face study did not consider whether participants would consider the potential partners for short- or long-term relationships: it evaluated general romantic interest only. Furthermore, there are differences in the specific traits examined across the different studies, which makes comparisons difficult.

Fletcher et al. (2004) asked their participants to choose between pairs of potential partners possessing different attributes. Participants had to make a trade-off among different traits (warmth/trustworthiness $\mathrm{x}$ attractiveness/vitality $\mathrm{x}$ status/resources). Overall, men and women placed great importance on warmth/trustworthiness regardless of whether a short- or long-term relationship was considered. However, when contrasted with attractiveness/vitality, men placed significantly more importance on attractiveness/vitality than did women for both short- and long-term relationships. When attractiveness was contrasted with low status, having to pick between an attractive partner with low status or a homely person with money and a high-status job, men preferred the attractive partner with low status more than did women. Overall, in comparison to men, women value warmth/trustworthiness and status/ resources more than attractiveness/vitality in a potential partner. Furthermore, sex differences were larger in the context of longterm than short-term mate choice.

Moreover, Li et al. (2002) demonstrated that sexdifferentiated preferences are most pronounced when individuals' choices are constrained. Specifically, men on a low "budget" prioritise attractiveness, whereas women prioritise resources and status. After the minimums for these attributes are met, individuals allocate their budget to other characteristics (e.g. similarity, intelligence). Therefore, partner preferences depend on sex, relationship contexts and on the degree to which choices are constrained.

Based on the studies discussed above, having the attributes that are attractive to the opposite sex would allow individuals to succeed in attracting a partner. An individual that possesses the ideal desirable attributes will be a fierce competitor in the mating attraction context, posing a greater threat to rivals (Borau and Bonnefon 2017). In the context of mate attraction, rivals' attributes affect intrasexual competition, such that the most desirable same-sex individuals are more frequently targeted as potential threats. Similarly, in the context of a romantic relationship, such desirable individuals as potential rivals would also pose a greater threat than less desirable ones, which could lead to the display of mate-retention behaviours. However, it is not clear how the assessment of potential rivals occurs, and which of their attributes would elicit specific mate-retention strategies.

\section{Intrasexual Competition and Mate Retention: the Threat of Mate Poachers}

Romantic relationships are susceptible to different problems that may threaten not only the quality of the relationship, but lead to its termination, such as different personalities, disagreements and long-distance (Apostolou et al. 2019). Although all of these factors are a source of concern for a couple, there is also the threat of mate poachers, which are individuals who attempt to attract someone who is already romantically committed to someone else (Schmitt 2004). Emotional and sexual extra-dyadic involvement is associated with relationship dissolution, even after controlling for age, relationship duration and relationship quality in non-married couples (Negash et al. 2014). Similarly, infidelity is the most common cause of marital dissolution in different societies (Betzig 1989; Fincham and May 2017; Ippoliti 2018). Infidelity results in negative outcomes for the individuals involved in the relationship, as well as to the offspring, such as depression and anxiety (Crouch and Dickes 2016). To avoid such costs, individuals use tactics to preserve their relationships, namely mate-retention strategies.

Mate-retention strategies range from positive strategies, such as oral sex (Pham and Shackelford 2013; Pham et al. 2013) and copulation (Barbaro et al. 2015) to negative strategies, such as violence against a partner and potential rivals (Buss and Duntley 2011). Thus, mate retention involves both intersexual - directed towards the romantic partner-and intrasexual behaviours - targeting potential romantic rivals (de Miguel and Buss 2011). Buss (1988) developed a taxonomy of mate retention to facilitate their assessment, 
identifying 19 tactics that can be grouped into five broader categories: direct guarding (e.g. vigilance), intersexualnegative inducements (e.g. emotional manipulation), positive inducements (e.g. display of love and care), public signs of possession (e.g. verbal signs of possession) and intrasexualnegative inducements (e.g. threatening rivals).

Many aspects affect a successful mate-poaching attempt. Dark triad personality traits (psychopathy, narcissism and Machiavellianism) of an individual positively predict successful mate poaching in men (Kardum et al. 2015). Davies and Shackelford (2017) found that a mate poacher's success depends on two main factors: (1) the level of commitment of the poached individual to their partners; and (2) the mate poacher's attributes. The greater the commitment of the poached individual to their partner, the higher the level of attractiveness and the amount of wealth necessary for the mate poacher to succeed. This means that not any poacher would successfully attract away someone else's partner: their attributes play an important part in the process, which means that those poachers who possess more desirable attributes will be more likely to succeed in poaching. If that is true, the partner of an individual would feel more threatened by more desirable rivals, and therefore, they would put more effort into protecting their relationship when such competitors are around, by displaying mate-retention strategies.

Research suggests that individuals' concern with mate retention rises when a potential rival displays attributes that suggest that such a rival could be a successful mate poacher. For example, women are sensitive to cues of other women's fertility and respond to them by displaying subtle materetention tactics, such as avoiding ovulating women, alongside reporting higher sexual desire for their own partners (Krems et al. 2016). Fink et al. (2014) observed that women with faces that are more feminine, with larger breasts and lower waist-to-hip ratios are perceived as more threatening by female observers, in line with the hypothesis that intrasexual competition focuses on the traits that the opposite sex finds more attractive. Because men find women with those attributes more attractive (Fletcher et al. 2004), other women will perceive them as a greater threat. Hennighausen et al. (2016) reported a similar process in men. Specifically, men prefer luxury cars compared to non-luxury ones and reported higher intentions to buy the luxury cars. More importantly, preference for luxury cars is greater in an intrasexual competition context, suggesting that men use luxury products in male-male competition to attract or retain partners.

\section{The Current Study}

In a committed relationship, both partners are subject to the threat of mate poachers and the strategies selected to protect their relationship against such threat will partly depend on the characteristics of the rival. If a man is more likely to be attracted to younger, attractive females, whenever there is such a competitor around, women will engage more often in mate-retention strategies than when less attractive women are around. The same should be true for men, if women place greater importance on power and status, for example, men will be more likely to display mate-retention behaviours when high-status rivals are around. In this study, we test whether potential rivals' attributes influence individuals' intentions to display mate-retention behaviours.

Whilst we have not found any studies experimentally manipulating rivals' attributes and their impacts on mate retention, Dijkstra and Buunk (2002) compared the effect of five attributes of rivals (social dominance, physical attractiveness, seductive behaviour, physical dominance and social status) on men and women's jealousy levels. Overall, they observed that men reported higher levels of jealousy when a rival was high in social dominance, physical dominance and social status. Women, on the other hand, reported to be more jealous when the rival was physically attractive. This confirms that heterosexual men and women will be particularly vigilant of those rivals possessing the attributes that they think the opposite sex values (Fink et al. 2014; Hennighausen et al. 2016). Because jealousy predicts mate-retention behaviours (Davis et al. 2018), we predict that compared to men, women will report higher intentions to use mate-retention behaviours when the rival is described as attractive. We also predict that men, compared to women, will report higher intentions to use mate retention when their rival has high-status. The five attributes of rivals used in the study of Dijkstra and Buunk (2002) have been shown to predict jealousy (see also Buunk et al. 2011) and represent different attributes that men and women value in a partner and so this study will also consider these five attributes for understanding materetention reactions to rivals' attributes.

Additionally, mate-poaching success depends on context. For example, mate poachers tend to be most successful when the relationship is long-distance and when the targeted mate is dating rather than married (Buss and Schmitt 2001). Mate poaching may also be sensitive to the environment as some situations that facilitate flirting (e.g. a party) may be more likely to result in infidelity than situations that do not (e.g. a conference). We hypothesise that participants in the party situation will report higher jealousy and higher intentions to perform mate retention than will participants in the conference situation.

\section{Method}

\section{Participants}

Participants consisted of 119 university students $(50.4 \%$ female, $n=60$, mean age $=21$ years, $\mathrm{SD}=9.5$ ), who were 
married or in a civil partnership $(54.9 \%, N=51)$ or dating or engaged $(45.1 \%, N=42)$. Participants were European (68.9\%), North American (14.3\%), 10.1\% East Asian and $6.7 \%$ were South American, North Asian or South Asian. Participants were recruited through a UK university recruitment system and through social network sites (e.g. Facebook).

\section{Materials}

Participants completed an online survey. The survey comprised the following measures:

Intentions to Perform Mate-Retention Behaviours (Adapted from Buss et al. 2008) We selected and adapted 10 items of the Mate Retention Inventory-Short-Form (MRI-SF) to evaluate the intentions to use mate-retention strategies. We selected two items for each of the five following matretention categories (Buss 1988; Buss et al. 2008): direct guarding (e.g. insist that my partner spend all her/his free time at the party/event with me); intersexual-negative inducements (e.g. show interest in other women/men to make my partner angry); positive inducements (e.g. display greater affection for my partner); public signs of possession (e.g. hold my partner's hand when other women/men were around); intrasexualnegative inducements (e.g. stare coldly at the man/woman who was looking at my partner). Participants indicated how likely it would be for them to use each of those strategies if another man/woman was flirting with their partner, using a scale ranging from 1 (not likely) to 4 (very likely). Similar to the MRI-SF, the 10 items combined offer a general score of intentions to use mate-retention strategies. As evidence of convergent validity, this general score significantly correlates with jealousy $(r=.53 ; p<.001)$. Additionally, the reliability of the scale was acceptable (Cronbach's $\alpha=.71$ ).

\section{Self-Perceived Mating Success Scale Landolt et al (1995) The} scale evaluates an individual's perception of the reactions they receive from members of the opposite sex (e.g. "Members of the opposite sex notice me", "Members of the opposite sex are attracted to me") and functions as a mate value measure. Responses were given on a seven-point scale ranging from 1 (Strongly disagree) to 7 (Strongly agree). The reliability of the scale was acceptable (Cronbach's $\alpha=.87$ ).

Jealousy Reaction to Rivals' Attributes This measure is an adapted version of the instrument of Buunk and Dijkstra (2015) and Dijkstra and Buunk (2002). We created the current version by selecting two items to represent each of the five attributes of rivals that individuals may find threatening, namely social dominance (spontaneous, popular), physical dominance (muscular, physically strong), physical attractiveness (attractive body, attractive face), social status (successful, has a good job) and seductive behaviour (seducer, behaves provocatively).
Participants were asked to rate how jealous they would feel if a potential rival that approached their partner possessed the attributes listed above on scale ranging from 0 [not jealous at all] to 5 [very jealous]. Participants were asked to report their level of jealousy for each of the attributes independently.

Self-Perceived Attributes Inventory To create this measure, we modified the scale of response and the instructions of the Rivals' Attributes Inventory described previously to investigate attributes that individuals may possess using 14 items that represent the five broad categories, namely social dominance (spontaneous, popular), physical dominance (muscular, physically strong), physical attractiveness (attractive body, attractive face), social status (successful, has a good job) and seductive behaviour (seducer, troublemaker). Participants were asked to report the extent to which they possess each of the attributes on a Likert scale ranging from 1 [low in this trait] and 7 [high in this trait]. Reliability coefficients ranged from .43 to .87 (Cronbach's alpha).

Scenario Creation To choose the two situations for the scenarios, five independent judges who were in a long-term relationship were asked to imagine a rival flirting with their partners in different situations using scenarios adapted from Dijkstra and Buunk 2002; Buunk and Dijkstra 2015). The judges rated the situations (e.g. party, conference, the opening of an art gallery) for their jealousy-evoking potential on a scale ranging from 1 (not jealous at all) to 7 (extremely jealous). Judges reported that they would feel the most jealous at a party $(M=5.20$; $\mathrm{SD}=.75)$ and the least jealous at an academic conference ( $M=3.20 ; S D=1.36)$. Therefore, these two situations were chosen as the scenarios to be used in the current study.

\section{Procedure}

This study followed a within- and between-subjects design, with all participants reporting their intentions to perform mate retention in response to different rivals' attributes in either a party or an academic event situation. Participants read a participant information sheet, in which research details such as procedure, confidentiality of data and the possibility of withdrawing at any time were explained. Next, female participants were presented with the following scenario (male participants were presented with the same scenario but with the genderterms changed appropriately)

You are at a party with your boyfriend and you are talking with some of your friends. You notice your boyfriend across the room talking to a woman that you do not know. You can see from her face that she is interested in your boyfriend. She is listening closely to what he is saying and you notice that she casually touches his hand. You notice that she is flirting with him. After a 
minute, your boyfriend also begins to act flirtatiously. You can tell from the way he is looking at her that he likes her a great deal. They seem completely absorbed in each other.

After reading the scenario, participants completed the jealousy reaction to rivals' attributes questionnaire. Female participants were then presented with a second scenario (male participants were presented with the same scenario but with the gender-terms changed appropriately) in which they were asked to imagine their partner interacting with a person of the opposite sex either at a party or an academic event situation, as follows:

Imagine that you are at a university party [academic event] with your partner. You are talking with some of your friends when you notice him across the room speaking with a person of the opposite sex that you do not know. As you watch him for a moment, you see this woman flirting with him. After a minute, he also begins to act flirtatiously. The two of them seem to be in their own world, not paying attention to anyone around them. He is looking at and speaking to her in a way that lets you know he finds her interesting.

After reading the scenarios, all participants were asked to imagine that their rivals possessed different attributes: (1) social dominance (e.g. spontaneous, popular); (2) physical dominance (e.g. muscular, physically strong); (3) physical attractiveness (e.g. attractive body, attractive face); (4) social status (successful, has a good job) and (5) seductive behaviour (e.g. seducer, troublemaker). For example, to imagine that the rival possessed dominant characteristics, female participants read the following passage (male participants were presented with the same scenario but with the gender-terms changed appropriately):

You find out that the woman he is flirting with is named M.K. M.K. is involved in many student organisations and appears to be very popular. She is spontaneous and charismatic, being invited to many parties since she has a large social circle and always appears to liven up any gathering.

Next, respondents completed the questionnaire assessing intentions to use mate-retention strategies in light of the threat to their relationship.

\section{Results}

Initially, we tested whether the attributes of the respondents play a role in how threatening they perceive each rival, examining whether their own attributes were associated with their jealousy levels and intentions to display mate retention in each condition. In men, their own level of attractiveness negatively correlated with jealousy towards socially dominant $(r=-.33, p<.001)$, physically dominant $(r=-.31$, $p<.001)$ and high-status rivals $(r=-.28, p<.001)$. Additionally, men's own level of seducing behaviours positively correlated with intention to perform mate-retention behaviours towards attractive rivals $(r=.28 ; p=.03)$. No significant correlations were found among women (all $r$ values $<.15$, all $p$ values $>.22$ ). No significant correlations were found between respondents' mate value and jealousy or intentions to engage in mate-retention behaviours neither in men nor in women (all $r$ values $<.19$, all $p$ values $>.13$ ).

\section{Effect of Sex, Situation and Rivals' Attributes on Jealousy}

A 2 (participant sex: male vs female) $\times 2$ (situation: academic party vs university event) $\times 5$ (rival characteristics: social dominance, physical dominance, physical attractiveness, social status and seductive behaviour) mixed model ANOVA on jealousy was performed. A significant main effect of rivals' characteristics was observed $[F(4,112)=24.49, p<.001$; $\left.\eta^{2}=.17\right)$. Follow-up tests exploring this finding (alpha corrected to $p<.005$, using a Bonferroni correction) demonstrated that participants reported more jealousy in the presence of attractive rivals $(M=4.54, \mathrm{SD}=1.58)$ than rivals possessing all the other attributes [social dominance $M=$ $4.90, \mathrm{SD}=1.42, t(118)=3.47, p=.001$; seductive behaviour $M=3.88, \mathrm{SD}=1.87, t(118)=7.28, p<001$; high-status $M=$ $3.92, \mathrm{SD}=1.63, t(118)=7.41, p<.001$; physically dominant $M=3.88, \mathrm{SD}=1.68, t(118)=7.47, p<.001)$. Participants also demonstrated higher levels of jealousy towards a socially dominant rival than towards all the other attributes [all $t$ values $>3.47=p<.001$ ), except in comparison attractiveness rivals. An interaction between sex and rivals' characteristics was also observed $\left[F(4,112)=25.43, p<.001 ; \eta^{2}=.15\right)$.

To explore the between-subjects effect, independent $t$ tests were carried out using a Bonferroni correction for multiple comparisons (adjusted $p=.01$ ). Women reported significantly higher levels of jealousy towards socially dominant rivals $[M=5 ; \mathrm{SD}=1.07, t(117)=-3.33, p<.001]$ and towards rivals expressing seductive behaviours $[M=4.35$; $\mathrm{SD}=1.73$; $t(117)=-2.82, p=.006]$ than did men (respectively $M=$ 4.07, $\mathrm{SD}=1.86 ; M=3.41, \mathrm{SD}=1.9$ ). Paired $t$ tests were carried out to explore the within-subjects effect (adjusted $p<.005)$. Men reported higher levels of jealousy towards attractive $(M=4.63, \mathrm{SD}=1.60)$ than towards a socially dominant $[M=4.07, \mathrm{SD}=1.86 ; t(58)=-3.47, p=.001]$, highstatus $[M=4.05, \mathrm{SD}=1.76, t(58)=3.39, p=.001]$ and seductive rivals $[M=3.41, \mathrm{SD}=1.90, t(58)=5.71, p<.001]$. They also reported more jealousy towards a physically dominant 
$[M=4.44, \mathrm{SD}=1.67 ; t(58)=4.8, p=.001]$ and high-status rival $[t(58)=3.26, p=.002]$ than a seductive rival. Differences between jealousy towards a physically dominant rival and a socially dominant $[t(58)=2.47, p=.03]$ and a high-status rival were observed $[t(58)=2.43, p=.02]$ but did not survive a Bonferroni correction. In turn, women reported higher levels of jealousy towards a socially dominant $(M=5, \mathrm{SD}=1.07)$ rival than a physically dominant $[M=$ 3.33, $\mathrm{SD}=1.52, t(59)=8.22, p<.001]$, high-status $[M=$ $3.80, \mathrm{SD}=1.49, t(59)=7.22, p<.001]$ and seductive rival $[M=5.17, \mathrm{SD}=1.18, t(59)=3.20, p=.002)$. They also reported higher levels of jealousy towards a physically attractive $(M=5.17, \mathrm{SD}=1.18)$ rival than towards a physically dominant $[t(59)=9.22, p<.001]$, high-status $[t(59)=4.57$, $p<.001]$ and seductive rival. Women also reported higher levels of jealousy towards a seductive rival than a physically dominant rival $[t(59)=4.28, p<.001]$. Differences between jealousy towards a high-status rival and jealousy towards a physically dominant $[t(58)=2.56, p=.01]$ and a seductive rival were observed $[t(58)=2.31, p=.02]$ but did not survive a Bonferroni correction.

A 2 (sex: male vs female) $\times 2$ (situation: academic party vs university event) $\times 5$ (rival characteristics: social dominance, physical dominance, physical attractiveness, social status, seductive behaviour) mixed ANCOVA on jealousy was performed, controlling for self-perceived mating success and scores on self-perceived attributes. This analysis did not return a significant main effect of rivals' characteristics on mate retention $[F(4,106)=.63, p=.61)$. The interaction between sex and rivals' characteristics remained significant $[F(4,106)=14.61$, $\left.p<.001, \eta^{2}=.12\right)$. The effect of participants' self-perceived seducing behaviours on jealousy was marginally significant $[F(4,106)=2.42, p=.06)$. The effects of the remaining covariates and the interactions between situation and rivals' characteristics and between these two variables and sex were nonsignificant (all $F$ values $<1.40$, all $p$ values $>.24$ ).

\section{Effect of Sex, Situation and Rivals' Attributes on Mate-Retention Behaviours}

Initially, a 2 (participant sex: male vs female) $\times 2$ (situation: academic party vs university event) $\times 5$ (rival characteristics: social dominance, physical dominance, physical attractiveness, social status, seductive behaviour) mixed ANOVA on mate-retention strategies was performed. A main effect of rivals' characteristics on mate retention was observed $\left[F(4,112)=11.59, p<.001 ; \eta^{2}=.09\right]$. Follow-up tests (adjusted $p<.005)$ demonstrated that intentions to use mate-retention behaviours are higher in the presence of an attractive rival $(M=2.20, \mathrm{SD}=.57)$ than rivals possessing all the other attributes [social dominance $M=2.08, \mathrm{SD}=.47, t(118)=4.32$, $p<.001$; status $M=2.02, \mathrm{SD}=.53, t(118)=5.65, p<.001$; physical dominance $[M=2.05, \mathrm{SD}=.58, t(118)=4.48$, $p<.001]$, apart from seductive rivals $[M=2.16, \mathrm{SD}=.64$, $t(118)=1.20, p=.23]$. In turn, intentions to use materetention behaviours are higher in the presence of a seductive rival than a physically dominant $[t(118)=3.09, p<001]$ or a high-status rival $[t(118)=3.72, p<001]$, but do not differ from intentions around socially dominant $[t(118)=2.15$, $p=.03$ ] or physically attractive rivals. An interaction between sex and rivals' characteristics was also observed $[F(4,112)=$ 6.16, $\left.p<.001 ; \eta^{2}=.05\right]$.

To explore the between-subjects effect, independent $t$ tests were carried out (adjusted $p<.01$ ) and, contrary to the current hypothesis, no significant differences emerged between men's and women's scores of mate retention for each of the rivals' characteristics (all $t$ values $<1.82$, all $p$ values $<.30$; see Fig. 1). Paired $t$ tests were carried out to explore withinsubjects effect (adjusted $p<.005$ ). Among men, a significant difference between the frequency of mate retention around an attractive $(M=2.11, \mathrm{SD}=.57)$ and a physically dominant rival $[M=2.04 ; \mathrm{SD}=.57, t(58)=2.88, p=.006]$ was observed. A difference between mate retention around a high-status $(M=$ 2.04; $\mathrm{SD}=.54)$ and an attractive rival $[t(58)=2.54, p=.01]$ was observed but did not survive a Bonferroni correction. Women reported performing mate-retention strategies more often in the presence of an attractive rival $(M=2.30$, $\mathrm{SD}=.56)$ than a socially dominant $[M=2.11, \mathrm{SD}=.47$, $t(59)=4.76, p<.001]$, high status $(M=2.01, \mathrm{SD}=.52)$ $[t(59)=5.37, p<.001]$ and physically dominant rival $[M=$ $2.08, \mathrm{SD}=.59, t(59)=3.82, p<.001]$. They also reported to perform mate-retention strategies more often in the presence of a seductive rival $(M=2.27, \mathrm{SD}=.62)$ than a high-status $[t(59)=4.19, p<.001]$ rival and a physically dominant rival $[t(59)=3.35, p<.001]$ (see Fig. 1). A difference between mate retention around a socially dominant and a high-status rival was found but did not survive a Bonferroni correction $[t(59)=2.73, p=.008]$.

The interactions between situation and rivals' characteristics and between these two variables and sex were non-significant ( $F$ values, all $p$ values $>.22$ ). The situation did not significantly affect the intensity of mate-retention strategies.

A 2 (participant sex: male vs female) $\times 2$ (situation: academic party vs university event) $\times 5$ (rival characteristics: social dominance, physical dominance, physical attractiveness, social status, seductive behaviour) mixed ANCOVA on materetention strategies was performed, controlling for selfperceived mating success and scores on self-perceived attributes. This analysis did not return a significant main effect of rivals' characteristics on mate retention $[F(4,106)=3.084$, $p=.84]$. The interaction between sex and rivals' characteristics remained significant $\left[F(4,106)=5.31, p=.001 ; \eta^{2}=.05\right]$. The effects of the covariates and the interactions between situation and rivals' characteristics and between these two variables and sex were non-significant (all $F$ values $<1.64$, all $p$ values $>.17$ ). 
Fig. 1 Frequency of mate retention for each rival attribute in men and women

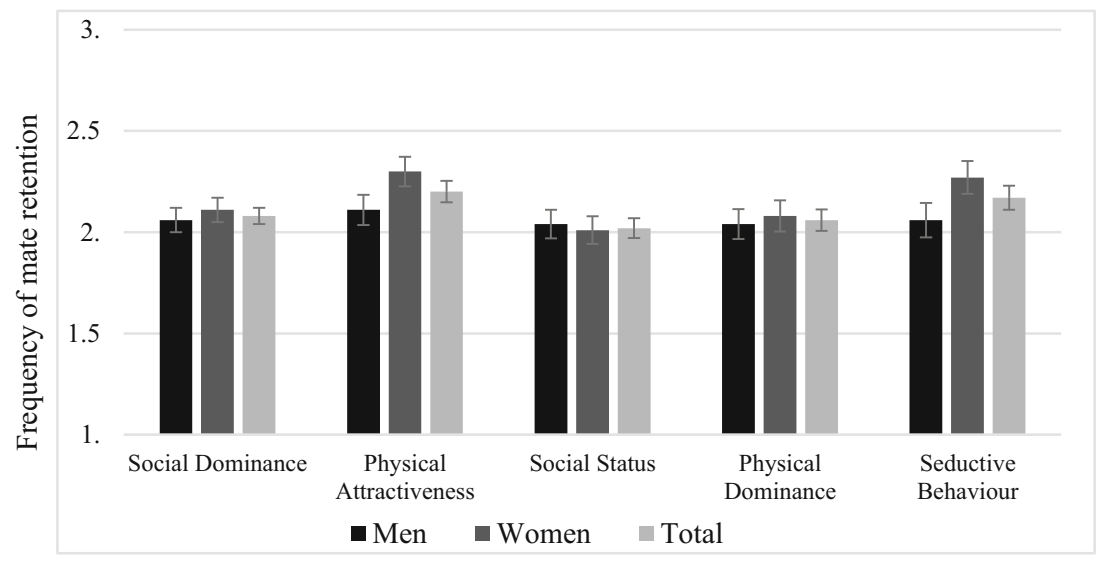

\section{Discussion}

This study investigated whether the attributes of a potential rival influence the use of mate-retention strategies. To manipulate such attributes, participants read a scenario in which their partner was potentially flirting with an opposite-sex stranger. Following the scenario, participants imagined their rivals having five broad attributes (social dominance, physical attractiveness, physical dominance, high status and seductive behaviour). For each attribute, participants reported how jealous they would be if the person talking to their partners possessed those attributes and how likely they were to use different mate-retention behaviours. The situation was also manipulated as participants were asked to imagine their partner and their rival flirting either at a party or at an academic conference. Results demonstrated that the rivals' attributes play a role in participants' levels of jealousy and frequency of materetention behaviours. These results varied according to the sex of participants but not according to the situation.

Regarding the main effect of rivals' attributes, individuals reported higher levels of jealousy towards attractive and socially dominant rivals in comparison to the other attributes, in line with previous studies on jealousy (Dijkstra and Buunk 2002). Similarly, for mate retention, participants reported higher intentions to use mate-retention strategies when threatened by attractive and seductive rivals. Taken together, these results suggest that rivals' attributes, particularly their physical attractiveness, play an important role in the intensity of materetention behaviours. One potential reason for participants' focus on such attributes may be that in a brief interaction, such as the one described in the scenario, these characteristics would be an important determinant for the success of a mate poacher. In fact, previous research has shown that both men and women place more importance on physical attractiveness and sexual desirability (e.g. attractiveness, sex drive) when selecting a partner, particularly for a short-term relationship (Eastwick and Finkel 2008; Selterman et al. 2015; Regan et al. 2000). Therefore, if a rival is attractive, extroverted and behaves seductively, they will have more chance to attract a potential mate, even if these potential mates are already taken. Following this, threatened partners will target rivals possessing these attributes through jealousy and mate guarding.

An interaction was also found between rivals' attributes and the sex of the participant for jealousy. Specifically, women reported higher levels of jealousy towards socially dominant and seductive rivals than men did. This may be because a more self-confident and spontaneous woman may more actively compete for the attention of another woman's partner (Dijkstra and Buunk 2002). Overall, women reported higher levels of jealousy than men, potentially because men are more likely to succumb to mate poaching (Adair et al. 2017). Additionally, it may be that men perceive more extroverted and seductive women as sexually available; therefore, these women would be more likely to succeed in attracting one's partner, explaining why women target these rivals more than men do. Moreover, the rivals' characteristics affected jealousy differently in men and women. In men, the attractiveness of rivals appeared to play a more important role in their jealousy level in comparison to the other characteristics. Although seductive behaviours seem to play a role for both men and women, for men only, physical dominance and high-status also appeared to make men more jealous than seductive behaviours. This is not surprising, since women seek these attributes more than men do (Little et al. 2008; Salmon 2017). Women, similarly to men, will respond more strongly either with jealousy or with mate-retention strategies, to an attractive and socially dominant rival in comparison to the other attributes. However, in contrast to men, a seductive rival was more threatening than both a higher-status and a physically dominant female, in line with the findings of Dijkstra and Buunk (2002).

There was also an interaction between sex and rivals' attributes for mate-retention behaviours. We hypothesised that women would report higher intentions to use mate-retention strategies when the rival is described as attractive than would men, whereas men would do so in the presence of a highstatus rival more than women would. However, no significant 
differences were found between the frequency of materetention behaviours for each rival attribute between men and women. Women reported slightly higher intentions to use mate retention with an attractive rival than did men; however, this was not statistically significant. On the other hand, men's and women's intentions to use mate-retention tactics were similar when the rival was depicted as possessing highstatus. Although this seems surprising initially, Hudders et al. (2014) found that women use luxury consumption as a selfpromotion strategy in an intrasexual competition context because this improves their chances against competitors, suggesting that women feel intimidated by a high-status rival in a similar way to men.

The study demonstrated that men reported greater intentions to use mate-retention strategies around a physically attractive rival than a physically dominant rival. Women, on the other hand, feel equally threatened by an attractive and a seductive rival. Women reported greater intentions to use materetention strategies around an attractive and seductive rival than around a rival with all the other attributes. However, the level of women's intentions to use mate-retention strategies did not significantly differ in response to rivals displaying seductive behaviours versus them displaying social dominance. These findings demonstrate that whilst attractiveness plays an important role for both men and women (Selterman et al. 2015), women feel particularly threatened by rivals that are more extroverted and behave seductively. This may be because women who behave more seductively have higher chances of luring someone's partner away, explaining why female respondents would focus their efforts on these rivals. At the same time, socially dominant women are more attractive for men as long-term partners (Regan et al. 2000), helping to explain why women target socially dominant rivals. Alternatively, participants may be expressing more concerns towards those attributes that they value themselves in a partner, and, therefore, feeling more threatened by rivals displaying such attributes.

The current study also investigated whether participants' own attributes and mate value would play a role in their jealousy and mate-retention reactions to rivals' attributes. The current study did not find any significant associations between women's attributes and mate value and their level of jealousy or intentions to perform mate retention. This finding contrasts with previous research suggesting that women are more likely to engage in social comparison (Dijkstra and Buunk 2002), and therefore their own attributes and mate value would play a role in how threatened they feel by rivals. On the other hand, there was a negative correlation between men's self-reported attractiveness and their jealousy towards social dominance, physical dominance and high-status in potential poachers. This suggests that men's jealousy depends not only on their potential rivals' attributes, but also on their own. Indeed, after controlling for mate value and participants' self-perceived attributes, the main effect of rivals' attributes on jealousy and mate retention became non-significant. Such findings corroborate previous research suggesting that successful mate poaching depends on the relative mate value of the poacher to the current partner's mate value (Davies and Shackelford 2017). Therefore, individuals' reactions to threats to their relationships depend on their own self-perceived value as a mate, at least in men.

This study has several limitations. First, although we randomly allocated our participants to either an academic conference or party situation, we used a convenience sample (i.e. non-random internet recruitment so participants are self-selected), which can limit the generalisability of the current findings. Whilst not addressed here, there may be variation across cultures (Nascimento and Little 2019) and future studies can examine if the relationship between rivals' characteristics and jealousy are similar or different across cultures. Another limitation is the use of self-report measures, which are subject to social desirability and which may have influenced participants' honesty to admit the performance of negative mate-retention strategies. For example, participants will be less likely to admit that they would slap someone else's face to protect their relationships against threats. Additionally, in each scenario, we have highlighted one isolated and specific attribute for the rivals. However, in real life, rivals are more complex and possess a mixture of different traits and attributes. When these attributes are combined, they may trigger different mate-retention strategies to those considered in the current study. Therefore, the extent to which the current findings may be applied to naturalistic contexts is limited.

Despite such limitations, this study represents an initial attempt to manipulate rivals' attributes to understand their impact on mate-retention behaviours. This is important for two reasons. First, studies on mate selection, attraction and retention usually focus on two attributes: attractiveness and status. This study has addressed a wider range of attributes and demonstrated how attributes such as social dominance and seductive behaviours influence intentions to perform mate-retention behaviours. The second is that studies on mate retention have been mainly correlational whereas the current study examined this topic experimentally. Taken together, the current findings help confirm the findings of previous studies demonstrating the evolutionary function of jealousy and mate retention as adaptive mechanisms designed to detect and deal with potential threats to a relationship.

Funding Information This research was funded by Capes Foundation, Ministry of Education —-Brazil (99999.001967/2015-00).

\section{Compliance with Ethical Standards}

Conflict of Interest The authors declare that they have no conflict of interest. 
Open Access This article is distributed under the terms of the Creative Commons Attribution 4.0 International License (http:// creativecommons.org/licenses/by/4.0/), which permits unrestricted use, distribution, and reproduction in any medium, provided you give appropriate credit to the original author(s) and the source, provide a link to the Creative Commons license, and indicate if changes were made.

\section{References}

Adair, L., Dillon, H. M., \& Brase, G. L. (2017). I'll have who she's having: mate copying, mate poaching, and mate retention. In M. L. Fisher (Ed.), The Oxford Handbook of Women and Competition (pp. 319-336). Oxford: Oxford University Press.

Apostolou, M., Constantinou, C., \& Anagnostopoulos, S. (2019). Reasons that could lead people to divorce in an evolutionary perspective: evidence from Cyprus. Journal of Divorce \& Remarriage, 60(1), 27-46. https://doi.org/10.1080/10502556.2018.1469333.

Barbaro, N., Pham, M. N., \& Shackelford, T. K. (2015). Solving the problem of partner infidelity: individual mate retention, coalitional mate retention, and in-pair copulation frequency. Personality and Individual Differences, 82, 67-71. https://doi.org/10.1016/j.paid. 2015.02.033.

Betzig, L. (1989). Causes of conjugal dissolution: a cross-cultural study. Current Anthropology, 30(5), 654-676 https://www.jstor.org/stable/ 2743579.

Borau, S., \& Bonnefon, J. F. (2017). The imaginary intrasexual competition: advertisements featuring provocative female models trigger women to engage in indirect aggression. Journal of Business Ethics, 157, 1-19. Retrieved from. https://doi.org/10.1007/ s10551-017-3643-y.

Buss, D. M. (1988). From vigilance to violence: tactics of mate retention in American undergraduates. Ethology and Sociobiology, 9, 291317. https://doi.org/10.1016/0162-3095(88)90010-6.

Buss, D. M., \& Duntley, J. D. (2011). The evolution of intimate partner violence. Aggression and Violent Behavior, 16(5), 411-419. https:// doi.org/10.1016/j.avb.2011.04.015.

Buss, D. M., \& Schmitt, D. P. (1993). Sexual strategies theory: an evolutionary perspective on human mating. Psychological Review, 100(2), 204-232. https://doi.org/10.1037/0033-295X.100.2.204.

Buss, D. M., \& Schmitt, D. P. (2018). Mate preferences and their behavioral manifestations. Annual Review of Psychology, 70, 77-110. https://doi.org/10.1146/annurev-psych-010418-103408.

Buss, D. M., Shackelford, T. K., \& McKibbin, W. F. (2008). The mate retention inventory-short form (MRI-SF). Personality and Individual Differences, 44, 322-334. https://doi.org/10.1016/j.paid. 2007.08.013.

Buunk, A. P., \& Dijkstra, P. (2015). Rival characteristics that provoke jealousy: a study in Iraqi Kurdistan. Evolutionary Behavioral Sciences, 9(2), 116-127. https://doi.org/10.1037/ebs0000030.

Buunk, A. P., Castro Solano, A., Zurriaga, R., \& González, P. (2011). Gender differences in the jealousy-evoking effect of rival characteristics: a study in Spain and Argentina. Journal of Cross-Cultural Psychology, 42(3), 323-339. https://doi.org/10.1177/ 0022022111403664.

Campbell, A. (2013). A mind of her own: the evolutionary psychology of women. Oxford: Oxford University Press.

Conroy-Beam, D., Goetz, C. D., \& Buss, D. M. (2016). What predicts romantic relationship satisfaction and mate retention intensity: mate preference fulfillment or mate value discrepancies? Evolution and Human Behavior, 37(6), 440-448. https://doi.org/10.1016/j. evolhumbehav.2016.04.003.
Crouch, E., \& Dickes, L. (2016). Economic repercussions of marital infidelity. International Journal of Sociology and Social Policy, 36(1/2), 53-65. https://doi.org/10.1108/IJSSP-03-2015-0032.

Darwin, C. (1871). The descent of man. London: John Murray.

Davies, A. P., \& Shackelford, T. K. (2017). Don't you wish your partner was hot like me?: the effectiveness of mate poaching across relationship types considering the relative mate-values of the poacher and the partner of the poached. Personality and Individual Differences, 106, 32-35. https://doi.org/10.1016/j.paid.2016.10.029.

Davis, A. C., Desrochers, J., DiFilippo, A., Vaillancourt, T., \& Arnocky, S. (2018). Type of jealousy differentially predicts cost-inflicting and benefit-provisioning mate retention. Personal Relationships, 25(4), 596-610. https://doi.org/10.1111/pere.12262.

de Miguel, A., \& Buss, D. M. (2011). Mate retention tactics in Spain: personality, sex differences, and relationship status. Journal of Personality, 79, 563-586. https://doi.org/10.1111/j.1467-6494. 2011.00698.x.

Dijkstra, P., \& Buunk, B. P. (2002). Sex differences in the jealousyevoking effect of rival characteristics. European Journal of Social Psychology, 32(6), 829-852. https://doi.org/10.1002/ejsp.125.

Eastwick, P. W., \& Finkel, E. J. (2008). Sex differences in mate preferences revisited: do people know what they initially desire in a romantic partner? Journal of Personality and Social Psychology, 94(2), 245-264. https://doi.org/10.1037/0022-3514.94.2.245.

Fincham, F. D., \& May, R. W. (2017). Infidelity in romantic relationships. Current Opinion in Psychology, 13, 70-74. https://doi.org/10.1016/ j.copsyc.2016.03.008.

Fink, B., Klappauf, D., Brewer, G., \& Shackelford, T. K. (2014). Female physical characteristics and intra-sexual competition in women. Personality and Individual Differences, 58, 138-141. https://doi. org/10.1016/j.paid.2013.10.015.

Fletcher, G. J., Tither, J. M., O’Loughlin, C., Friesen, M., \& Overall, N. (2004). Warm and homely or cold and beautiful? Sex differences in trading off traits in mate selection. Personality and Social Psychology Bulletin, 30(6), 659-672. https://doi.org/10.1177/ 0146167203262847.

Hennighausen, C., Hudders, L., Lange, B. P., \& Fink, H. (2016). What if the rival drives a Porsche? Luxury car spending as a costly signal in male intrasexual competition. Evolutionary Psychology, 14(4), 113. https://doi.org/10.1177/1474704916678217.

Hudders, L., De Backer, C., Fisher, M., \& Vyncke, P. (2014). The rival wears Prada: luxury consumption as a female competition strategy. Evolutionary Psychology, 12(3), 147470491401200. https://doi.org/ $10.1177 / 147470491401200306$.

Ippoliti, R. (2018). Human mating theory, migration, and marital dissolution. Archives of Sexual Behavior, 47(3), 747-755. https://doi.org/ 10.1007/s10508-017-1087.

Kardum, I., Hudek-Knezevic, J., Schmitt, D. P., \& Grundler, P. (2015). Personality and mate poaching experiences. Personality and Individual Differences, 75, 7-12. https://doi.org/10.1016/j.paid. 2014.10.048.

Kirsner, B. R., Figueredo, A. J., \& Jacobs, W. J. (2003). Self, friends, and lovers: structural relations among Beck Depression Inventory scores and perceived mate values. Journal of Affective Disorders, 75(2), 131-148. https://doi.org/10.1016/S0165-0327(02)00048-4.

Krems, J. A., Neel, R., Neuberg, S. L., Puts, D. A., \& Kenrick, D. T. (2016). Women selectively guard their (desirable) mates from ovulating women. Journal of Personality and Social Psychology, 110(4), 551-573. https://doi.org/10.1037/pspi0000044.

Landolt, M. A., Lalumière, M. L., \& Quinsey, V. L. (1995). Sex differences in intra-sex variations in human mating tactics: an evolutionary approach. Ethology and Sociobiology, 16, 3-23. https://doi.org/ 10.1016/0162-3095(94)00012-V.

Li, N. P., Bailey, J. M., Kenrick, D. T., \& Linsenmeier, J. A. (2002). The necessities and luxuries of mate preferences: testing the tradeoffs. 
Journal of Personality and Social Psychology, 82(6), 947-955. https://doi.org/10.1037/0022-3514.82.6.947.

Little, A. C., Jones, B. C., \& DeBruine, L. M. (2008). Preferences for variation in masculinity in real male faces change across the menstrual cycle: women prefer more masculine faces when they are more fertile. Personality and Individual Differences, 45(6), 478482. https://doi.org/10.1016/j.paid.2008.05.024.

Millar, M., Westfall, R. S., \& Lovitt, A. (2018). The influence of mate value on women's desire for long and short-term mates: implicit responses. Personality and Individual Differences, 130, 36-40. https://doi.org/10.1016/j.paid.2018.03.043.

Miller, G. F. (1998). How mate choice shaped human nature: a review of sexual selection and human evolution. In C. Crawford \& D. L. Krebs (Eds.), Handbook of evolutionary psychology: ideas, issues, and applications (pp. 87-129). London: Lawrence Erlbaum Associates.

Nascimento, B. S., \& Little, A. C. (2019). Mate retention strategies, selfesteem, mate value and facial attractiveness disparity in Brazil and in the UK. Journal of sex \& Marital Therapy, 1-12. https://doi.org/10. 1080/0092623X.2018.1557307.

Negash, S., Cui, M., Fincham, F. D., \& Pasley, K. (2014). Extradyadic involvement and relationship dissolution in heterosexual women university students. Archives of Sexual Behavior, 43(3), 531-539. https://doi.org/10.1007/s10508-013-0213-y.

Pham, M. N., \& Shackelford, T. K. (2013). Oral sex as mate retention behavior. Personality and Individual Differences, 55, 185-188. https://doi.org/10.1016/j.paid.2013.02.012.
Pham, M. N., Shackelford, T. K., \& Sela, Y. (2013). Women's oral sex behaviors and risk of partner infidelity. Personality and Individual Differences, 55, 446-449. https://doi.org/10.1016/j.paid.2013.04. 008.

Regan, P. C., Levin, L., Sprecher, S., Christopher, F. S., \& Gate, R. (2000). Partner preferences: what characteristics do men and women desire in their short-term sexual and long-term romantic partners? Journal of Psychology and Human Sexuality, 12(3), 1-21. https:// doi.org/10.1300/J056v12n03_01.

Salmon, C. (2017). Long-term relationships: adaptationist approaches. Evolutionary Behavioral Sciences, 11(2), 121-130. https://doi.org/ 10.1037/ebs0000081.

Schmitt, D. P., \& Buss, D. M. (2001). Human mate poaching: Tactics and temptations for infiltrating existing mateships. Journal of personality and Social Psychology, 80(6), 894. https://doi.org/10.1037/00223514.80.6.894.

Schmitt, D. P. (2004). Patterns and universals of mate poaching across 53 nations: the effects of sex, culture, and personality on romantically attracting another person's partner. Journal of Personality and Social Psychology, 86(4), 560-584. https://doi.org/10.1037/0022-3514.86. 4.560 .

Selterman, D. F., Chagnon, E., \& Mackinnon, S. P. (2015). Do men and women exhibit different preferences for mates? A replication of Eastwick and Finkel (2008). SAGE Open, 5(3), 215824401560516 . https://doi.org/10.1177/2158244015605160.

Publisher's Note Springer Nature remains neutral with regard to jurisdictional claims in published maps and institutional affiliations. 